nor therapy had any effect on the rate of decline of F.E.V. or on the volume or purulence of sputum specimens.

We wish to record our appreciation to Pfizer Limited for their generous supply of oxytetracycline and indistinguishable dummy tablets, and for their willing cooperation in the analysis of numerous blood and urine samples for oxytetracycline, both before and during the trial ; and to Messrs. Parke Davis and Co. for their supply of chloramphenicol, sulphamethoxypyridazine, and penicillin capsules. Numerous members of the staff of the Pneumoconiosis Research Unit assisted with the packing and dispatch of over a million tablets, but the main burden of this work fell on Mrs. J. P. Duimovich, who also kept the statistical records of the trial. We would life to thank the officers of the Ministry of Pensions and National Insurance who provided us with records of the sickness absence of the patients in the trial, and the staff and health visitors of the different clinics for their continual help, especially for the extra evening sessions that were necessary, since the patients were nearly all at work during the day.

The participating clinics and hospitals were: Postgraduate Medical School, Hammersmith Hospital, London W.12; Department of Respiratory Diseases and Tuberculosis, University of Edinburgh; Leeds Chest Clinic; Whinney House Hospital, Gateshead; the Marsden Hospital, Burnley ; the Central Middlesex Hospital, London N.W.10 ; Central Chest Clinic, Southampton; Worcester Royal Infirmary ; Corbett Hospital, Stourbridge, Worcs ; Department of Therapeutics and Pharmacology, the Queen's University of Belfast ;
Chorley Chest Clinic, Chorley, Lancs; High Carley Hospital, Ulverston, Lancs; Norwich and East Norfolk Chest Clinic, Norwich.

Communications concerning the Report should be sent to the Medical Research Council, 20 Park Crescent, London W.1.

\section{REFERENCES}

Brit. med. 7., 1964, 1, 718. Edwards, G., Buckley, A. R., Fear, E. C., Williamson, G. M., and
Zinnemann, K. (1957). Brit. med. 7., 2, 259.

Elmes, P. C., Dutton, A. A. C., and Fletcher, C. M. (1959). Lancet, 1, (1241.

Fear, E. C., and Edwards, G. (1962). Brit. 7. Dis. Chest, 56, 153.

Ferris, B. G., Anderson, D. O., and Zickmantel, R. (1965). Amer. Rev. resp. Dis., 91, 252.

Finney, D. J.'(1941). F. roy. statist. Soc., Suppl. No. 7, p. 155.

Fletcher, C. M. (1952). Proc. roy. Soc. Med., 45, 577.

Francis, R. S., May, J. R., and Spicer, C. C. (1964). Brit. med. f., 1, 728.

Hill, I. D., Letchner, J., Tinker, C. M., and Fletcher, C. M. (1966). In preparation.

Holland, W. W. (1964). M.D. Thesis. London.

- and Reld, D. D. (1965). Lancet, 1, 445.

Kilpatrick, G. S., and Oldham, P. D. (1954). Brit. med. 7., 2, 385.

Medical Research Council (1960). Ibid., 2, 1665 .

Oldham, P. D. (1953). Brit. F. industr. Med., 10,227.

Scottish Health Services Council (1963). Bronchitis. Report of a Subcommittee of the Standing Medical Advisory Committee, p. 29. H.M.S.O., London.

Todd, G. F. (editor) (1962). Statistics of Smoking in the United Kingdom. Tobacco Manufacturers' Standing Committee. Research Papers No. 1, 3rd ed. London.

\title{
Massive Pulmonary Embolism in Healthy People
}

\author{
H. A. FLEMING,* M.D., M.R.C.P.; SHEILA M. BAILEY, $\dagger$ M.в., в.S.
}

Brit. med. F., 1966, 1, 1322-1327

In recent years many reports have indicated an increasing frequency of the diagnosis of pulmonary emboli. Short (1952), Gorham (1961), Barritt and Jordan (1960, 1961), Wilhelmsen et al. (1963), Goodwin et al. (1963), Morrell et al. (1963), Freiman et al. (1965), and Sasahara and Stein (1965) are representative examples from a vast literature. Until Thompson and Hamilton's paper in 1962 the occurrence of major pulmonary emboli in ambulant healthy people had received little general recognition. Many clinicians still fail to recognize this condition, and are prepared to make a diagnosis of pulmonary embolism only in the post-operative case, the case in gross heart failure, the bedridden, or the aged. This point is emphasized in the tragic report of Murphy (1963), and by the fact that three of our own severe but fortunately non-fatal cases were also doctors' wives in whom there was considerable delay in diagnosis.

This failure is mirrored in a number of otherwise excellent monographs and conference proceedings on the pulmonary circulation, and even one on pulmonary embolic disease, which have nothing whatever to say on fatal pulmonary embolism in healthy persons.

The frequency with which we made this clinical diagnosis led us to wonder if there were not a number of such patients who died either before diagnosis was made or before treatment could be effectively instituted (Fleming, 1962). This led to the present study of fatal cases, and of cases diagnosed and treated in life. \footnotetext{
* Consultant Cardiologist, East Anglian Regional Hospi:al Board and
Addenbrooke's Hospital, Cambridge.

† Research Assistant, East Anglian Regional Hospital Board and Adden-
brooke's Hospi:al, Cambridge.
}

Material
We first searched the necropsy reports of the Cambridge
University Department of Pathology for the years 1946-63.
This department carrics out all the necropsies in the Cambridge
area, and detailed reports are kept.
As this study was concerned only with healthy people all
those over 70 were excluded, as were those known to suffer
from predisposing disease or to have undergone recent surgery
or trauma. Minor surgery or surgery a few weeks previously
did not exclude some cases if the association was not obvious
to the doctor seeing the patient.
During $1946-63$ 9,280 necropsies were carried out, the
numbers rising steadily from 273 in 1946 to 857 in 1963.
Of these about 300 were classified as having massive pulmonary
emboli, and about 400 as having small pulmonary emboli.
Thirteen of these subjects had died suddenly outside hospital
and no other cause of death could be found. Three were over
the age of 70 , and one had a small abscess in the left upper
lobe. These were eliminated from the series, leaving nine cases
to be considered here. A further 18 cases fulfilling the criteria
of the study had been admitted to hospital before their death.
Thus there were 27 fatal cases for consideration-6 males and
21 females. The age range was 23 to 69 years (average 50).
Of the nine cases of sudden death outside hospital eight
were women, and all but one had a recorded complaint of some
dyspnoea or chest discomfort preceding death. The 23 -year-old
patient was five months pregnant, and had been treated for
venous thrombosis three and a half weeks previously.
In all cas

In all cases either a large embolus straddled the pulmonary artery bifurcation or both main pulmonary arteries were blocked 
by thrombus. In most cases an earlier thrombus was also present in peripheral branches with or without infarction.

Venous thrombosis was demonstrated at necropsy in all but one case, and its situation was as follows: deep veins of leg in 16 , uterine veins in 3 , pelvic veins in 3 , and superficial and deep veins in 4 .

Two patients were five months pregnant, and one was eight days post partum and had previously been toxaemic.

In six cases there was evidence of venous thrombosis at the time of hospital admission. In two cases venous thrombosis became evident after admission. The initial hospital diagnosis varied widely: pulmonary embolism in 3 , pneumonia in 6 , coronary thrombosis in 1 , deep-vein thrombosis in 3 , cerebral vascular accident in 1, gastro-intestinal haemorrhage in 1 , pulmonary hypertensive heart failure in 1 , secondary carcinoma of lung in 1 , and in 1 it was uncertain.

The duration of symptoms varied from a few hours to five months. Two cases followed ligation of varicose veins-one at five days and one at two weeks.

An electrocardiogram was carried out in six cases, and in all of them it was thought to be diagnostic.

\section{Clinical Cases (Part 1)}

One of us (H.A. F.) personally saw 39 cases of major pulmonary embolism out of a total of 5,213 new patients seen in the five-year period 1960-4. These were all healthy people fulfilling the same criteria as designated for those in the postmortem series. Diagnosis was made on the basis of the history and the physical signs, often with confirmation from the electrocardiogram or the chest $x$-ray films.

All the historical, clinical, electrocardiographic, radiological, and laboratory features of these cases were analysed in great detail, but in most cases this study showed nothing more than had been established by earlier reports, and in the interest of brevity are not reported here. The ages of these patients are given in Table $\mathrm{I}$.

\begin{tabular}{|c|c|c|c|c|c|c|c|c|}
\hline \multicolumn{2}{|c|}{ Age in Years : } & \multirow{2}{*}{$\frac{10-19}{0}$} & \multirow{2}{*}{$\frac{20-29}{1}$} & \multirow{2}{*}{$\begin{array}{c}30-39 \\
2 \\
8\end{array}$} & \multirow{2}{*}{$\begin{array}{c}40-49 \\
3 \\
5\end{array}$} & \multirow{2}{*}{$\begin{array}{c}50-59 \\
\begin{array}{c}6 \\
0\end{array}\end{array}$} & \multirow{2}{*}{$\begin{array}{c}60-70 \\
5 \\
2\end{array}$} & \multirow{2}{*}{$\begin{array}{c}\text { Total } \\
\begin{array}{c}17 \\
22\end{array}\end{array}$} \\
\hline $\begin{array}{l}\text { Male } \\
\text { Female }\end{array}$ & $\because$. & & & & & & & \\
\hline
\end{tabular}

Relation to Pregnancy.-Fifteen cases were related in time to a pregnancy (see Case 2). The stage of pregnancy was three months in 4 cases, seven to eight months in 4 , and post partum (nine days to three months) in 7. Two had a history of deep-vein thrombosis in previous pregnancy, one had hyperemesis, one toxaemia, one caesarean section, and one post-partum haemorrhage. There was thus a high incidence of complicated pregnancy. Most of the cases in women under the age of 45 were related to pregnancy.

Of the 39 cases $24(62 \%)$ had a history or clinical evidence of venous thrombosis, though in five this did not become evident until after the embolus had been diagnosed. Two cases had severe varicose veins without evidence of thrombosis. Seventeen patients (43\%) were overweight.

Presenting Symptoms.-These began from a few hours to seven years before the diagnosis was made, and were: chest pain in 19, dyspnoea in 15, faintness in 12 , and fatigue in 5. All were treated with anticoagulants and made a good recovery, though it was a long time before some patients regarded themselves as normal-for example, Case 3. Twelve still remain on anticoagulants.

The electrocardiogram was normal and remained so in 11 cases, but it showed some abnormality in 28 . On several occasions the changes were very transient, and were seen only in the tracing taken soon after the event. In another case sudden deterioration of the electrocardiographic changes were taken to be an indication of further embolus (Case 2), though there was no other change in the clinical features.

\section{Clinical Studies (Part 2)}

In an effort to study further the incidence of this disorder and its clinical features and prognosis the Addenbrooke's Hospital in-patient diagnostic index was searched for cases fulfilling our criteria in the period 1958-64. This search did not include the maternity hospital.

Of a total of 71,829 admissions 418 were indexed as cases of pulmonary emboli, and in 140 of these there was no other important diagnosis, but scrutiny of the case-notes reduced the number to 38 non-fatal cases fulfilling the criteria of this study. The ages of these patients are given in Table II. Again most of the cases in the younger women were related to pregnancy; two were at four months and three were post partum.

\begin{tabular}{|c|c|c|c|c|c|c|}
\hline \multicolumn{2}{|r|}{ Age in Years: } & 30-39 & $40-49$ & $50-59$ & $60-69$ & Total \\
\hline $\begin{array}{l}\text { Male ... } \\
\text { Female }\end{array}$ & $\begin{array}{ll} & . \\
. & \end{array}$ & $\begin{array}{l}2 \\
5\end{array}$ & $\begin{array}{l}2 \\
7\end{array}$ & $\begin{array}{l}3 \\
4\end{array}$ & $\begin{array}{l}9 \\
6\end{array}$ & $\begin{array}{l}16 \\
22\end{array}$ \\
\hline
\end{tabular}

There was clinical evidence of venous thrombosis in 29 cases $(76 \%)$; six followed stripping of varicose veins from four days to three weeks after the operation. Nine others gave a history of varicose veins, eight a history of previous leg-vein thrombosis, and three a history of previous pulmonary embolism.

Eleven were noted to be overweight, but often no mention was made of the patient's figure, and the actual number is likely to be greater.

The presenting symptoms were: chest pain in 32, dyspnoea in 8 , haemoptysis in 5 , cough in 3 , "pleurisy" in 2 , and faintness in 1 .

The physical signs, electrocardiogram, chest $x$-ray films, and laboratory findings were analysed in detail, but as they shed no new light on the condition they are not reported here.

Follozv-up.-Treatment was by anticoagulants in 32 cases, and varied in duration from two weeks to three months; it was long-term in only one case. Most patients showed rapid improvement, but four had further acute episodes while in hospital. Two made a very slow recovery and were left somewhat impaired. A long-term follow-up was carried out by means of a questionary sent to the general practitioner, and 35 of the 38 replied. Twenty-nine were alive and well, three were considerably improved, two had further emboli some years after the first episode, four had left the area and could not be traced. Thus, in spite of the anticoagulants not being continued, most of these patients did well. It would seem unprofitable to treat them all with long-term anticoagulants.

Pulmonary Hypertension.-In the period 1960-4 only six cases presented as isolated pulmonary hypertension. All were confirmed by cardiac catheterization, and the pulmonary vascular resistance ranged from 10 to 25 units. The age range was from 32 to 55 years (average 42); four were male and two female. In none was there a history of venous thrombosis or of symptoms of pulmonary embolism. Three died, only one showing post-mortem evidence of ante-mortem clot in the pulmonary vasculature. It is difficult to connect these cases with the embolic series.

\section{Case 1}

A 36-year-old previously fit wife of a doctor had three young children. Pregnancies four to ten years ago had been uneventful, and her history included a miscarriage followed by a dilatation and 
curettage, thrombophlebitis of the left leg, and, following this, stripping of the varicose veins. Two weeks before the relevant episode she underwent a simple appendicectomy, which was followed by a completely uneventful recovery. She had returned home and was actively looking after her house and family.

One morning she suddenly experienced very rapid and distressed breathing. She felt extremely faint and unwell, collapsed completely, became unconscious, and was found by her husband cyanosed and convulsing. After a short interval she recovered somewhat but remained ill. She was at once admitted to hospital, and by this time had a left-sided chest pain. The clinical signs included an extremely low cardiac output, with peripheral cyanosis, a raised jugular venous pressure, a right atrial gallop, a lift over the pulmonary artery with accentuation of the pulmonary second sound, and a loud pericardial rub over the pulmonary artery. The electrocardiogram showed extreme clockwise rotation, with an $\mathrm{rS}$ wave right over to $\mathrm{V} 7$ and with deep $\mathrm{T}$-wave inversion in V1-4. There was no sign of any venous thrombosis. She was treated with heparin, warfarin, and digitalis, and made a slow but uneventful recovery with a return of the physical signs and electrocardiogram to normal. The chest $x$-ray film showed cardiac enlargement and elevation of the right diaphragm.

\section{Case 2}

This 30-year-old woman was seen early in 1962. Four years proviously she had had an uneventful pregnancy. A year later she had been investigated for thyrotoxicosis with negative results.

When seen she was seven months pregnant, and had felt perfectly well until two days before. She then suddenly felt extremely faint and generally very weak, distressed, breathless, and ill. In fact she briefly lost consciousness. Thereafter she had made a gradual recovery until she felt normal.

On examination she was considerably overweight but otherwise appeared normal. She became dyspnocic on undressing. There was a tachycardia of 100 per minute, and the blood-pressure was $120 / 80$. The jugular venous pressure was raised slightly more than could be attributed to the pregnancy, and there was a prominent "a "wave. There was no lift over the pulmonary artery, but auscultation revealed a right atrial gallop and the second heart sound was normal. The left leg was a little dusky and swollen, and there was slight tenderness in the groin.

The electrocardiogram showed sinus rhythm with very considerable clockwise rotation, and the $T$ waves were inverted in V1-4.

She was admitted to hospital immediately and treated with heparin and phenindione. Initially the left leg became more swollen but then subsided. The electrocardiogram showed progressive improvement.

Anticoagulants were given during the rest of pregnancy, the level of control being slightly relaxed towards term. However, in spite of the absence of any additional clinical episode the electrocardiogram showed deterioration in $\mathrm{T}$-wave inversion over the right ventricular leads, and the anticoagulants were therefore pressed further. Delivery was uncomplicated, but in the early postpartum period there was another recurrence of leg-vein thrombosis before full anticoagulant control was achieved.

Anticoagulants were continued for three years, and the patient remains well.

\section{Case 3}

A 51-year-old coffee-planter, seen in England, complained of breathlessness after having been retired from work in East Africa on medical advice. In 1954 he sprained his right ankle, and it remained swollen for some months. Varicosities subsequently developed in the right leg, and ever since he has worn an elastic bandage.

Early in 1961, after playing in a cricket match, he became extrenely short of breath, and developed an irritable cough and left-sided chest pain. He was treated for bronchitis and emphysema but made little progress. Two weeks later, after getting out of bed one night, he suddenly lost consciousness and fell to the floor. When he came to he was aware of considerable dyspnoea, a dull central retrosternal pain, and a sharper pain in the left chest. He became progressively worse over the next two months: he was short of breath at rest and was cyanosed, this increasing on slight exertion. He had a marked gallop rhythm, a low-grade fever, and what would appear to have been the pain of hepatic congestion. Chest $x$-ray examination showed a considerable increase in the size of the main pulmonary arteries, with peripheral oligaemia. Diagnosis at that time included tonsillitis, emphysema with pulmonary hypertension, and anteroseptal myocardial infarction. Over the next three months he gradually improved but still remained somewhat dyspnoeic. Pulmonary function studies showed that his $\mathrm{CO}_{2}$ tension was low, the arterial oxygen saturation was $93.2 \%$, and there was some evidence of hyperventilation.

Review of the electrocardiogram taken during this illness showed clear evidence of pulmonary hypertension. In February there was an S1Q3 pattern with a $1-\mathrm{mm}$. $R$ wave in lead AVR. The T waves were inverted in V1-4, but the $Q$ wave appeared in V5. Three weeks later the S1Q3 pattern was much more pronounced, and there was a $3-\mathrm{mm}$. $R$ wave in lead AVR. The $T$ waves were still inverted in $\mathrm{V} 1-4$, and there was considerable clockwise rotation with no $Q$ wave visible in V7. Two months after this electrocardiogram the $R$ wave in lead AVR was $4 \mathrm{~mm}$. high, the $T$ waves were deeply inverted in V1-7, and V7 showed an rS pattern. Over the ensuing months these changes gradually reverted to near normal.

When seen in England he had some exercise intolerance, being able to walk only half a mile ( 800 metres) with comfort, and his legs continued to be swollen.

On examination he was rather obese, and his blood-pressure was 95/60; there was no sign of right ventricular hypertrophy, but auscultation revealed a pulmonary ejection click, a pulmonary systolic ejection murmur, and normal splitting of the second sound. Marked varicosities were present in both legs, which were also oedematous. The electrocardiogram was normal, and the chest $x$-ray film showed only some increase in the size of the pulmonary artery.

Cardiac catheterization was carried out in September 1961 ; the resting pulmonary artery pressure was $25 / 5$, with a mean of $13 \mathrm{~mm}$. Hg. The pulmonary vascular resistance was 1.5 units. After three minutes of leg-raising exercise the pulmonary artery pressure had risen to $38 / 15$, mean $22 \mathrm{~mm}$. $\mathrm{Hg}$.

$\mathrm{He}$ has been treated with anticoagulants ever since and has remained well. At the time of writing, five and a half years after the onset of his dyspnoea, he felt perfectly fit and was playing cricket.

\section{Discussion}

Our post-mortem study has demonstrated that fatal pulmonary embolism is not rare in healthy people. Correspondence and conversations with colleagues aware of our interest in this subject have also suggested that these cases are not rare in the experience of those alive to the possibility. Since our study was completed the paper of Breckenridge and Ratnoff (1964) has recorded a significant incidence in a younger age group than ours. They restricted their study to the necropsy records of patients between the ages of 15 and 45, and found 26 such cases over a 12-year period. They estimated that in this age group there was an incidence of 2.7 per million for males, 3.8 per million for females, and 2.7 per million for non-pregnant females. In a more general medical setting pulmonary embolism has an even greater frequency, and Freiman et al. (1965) suggest that in well over half of all human necropsies careful examination will demonstrate evidence of one or more pulmonary embolic episodes.

The literature shows that the theme of pulmonary emboli in healthy people has in fact been presented repeatedly for a number of years, though perhaps not with the vigour it deserves. Homans (1943) reported 11 cases of thrombus developing silently in the deep veins of the legs in healthy people whose first symptoms were those of pulmonary embolism or infarction. Hampton et al. (1945) reported 10 cases of pulmonary emboli from obscure sources. All these patients were healthy and at work, and none was admitted to hospital with the correct diagnosis. Short (1952) surveyed pulmonary embolism in a general hospital and reported 120 cases of embolism or infarction. Of these, three cases of embolism occurred without 
warning in apparently healthy persons and were admitted to hospital with a diagnosis of pneumonia. Cohen and Daly (1957) reported 10 similar cases, none of which presented with signs of peripheral thrombosis. The clinical picture was of recurrent attacks of pleurisy with haemoptysis not responding to antibiotics. Those treated with anticoagulants recovered, but three who were untreated died. Petch (1958) reported 11 cases seen in six years, and drew attention to the reluctance to recognize this condition in this country. Kilburn and Sieker (1958), over a period of five years, collected 25 men under the age of 40 suffering from recurrent pulmonary infarction in the absence of other disease. Three had a family history, two died, and five had evidence of pulmonary hypertension. Leg thrombophlebitis preceded the episode in 17 and followed it in two. This was often recurrent. Six had varicose veins.

Our post-mortem study demonstrated that prior to the fatal embolus there was often a period of intermittent symptoms, and necropsy frequently revealed emboli of varying ages. This has also been reported by Owen et al. (1953) and Smith et al. (1964). After the first clinical episode there may be a period of days or weeks when treatment can be instituted if the diagnosis can only be made. For this a high awareness of the possibility is necessary, and it would be very desirable to have the diagnosis confirmed by some objective test before the situation becomes dangerous or irreversible. In fact the clinical features may be minimal or absent, they may mimic other cardiorespiratory disease, and they may be mimicked by other disease (Medd and McBrien, 1962 ; Hamilton and Thompson, 1963). Differential diagnosis has been fully dealt with by other writers (Barritt and Jordan, 1961; Thompson and Hamilton, 1962 ; Barritt, 1964). The diagnosis is often made only on suspicion, and to one well aware of this condition it may be made with too great frequency. However, in most instances the diagnosis is overlooked until much too late. More objectivity is needed so that a firm diagnosis can be made and a rational scheme of management instituted.

A detailed study of the clinical features of our surviving cases revealed no useful information that had not already been reported-for example, Wood (1956), Parker and Smith (1958), and Barritt and Jordan (1961)-and for that reason we give no details here. We would, however, emphasize the importance of faintness, or syncope, and of tiredness as early symptoms in the group of patients presenting to a cardiologist.

\section{Diagnostic Methods}

The electrocardiogram has been much studied as a diagnostic tool in pulmonary embolism (Wood, 1956; Cutforth and Oram, 1958 ; Parker and Smith, 1958 ; Dunér et al., 1960a), and in general the appearances reported are consistent with acute right-heart strain or clockwise rotation. Electrocardiographic changes were of ten absent, and in other cases they were transient and could easily be missed if a record was not made at the crucial time. Where the changes were of the classical type of right-heart stress the situation was already very far advanced. These findings are in agreement with those of Littmann (1965), who states that probably not more than $10-20 \%$ of patients who subsequently turn out to have pulmonary embolism develop any electrocardiographic changes, and of these a still smaller number show identifiable diagnostic abnormalities.

Chest $x$-ray films were seldom diagnostic. Clinicians and radiologists are still liable to expect opacities in the lung field rather than the paucity of vascular markings on the affected side, which is more usual when embolus without infarction has occurred. An appearance of plethora on the normal side may also be observed (Torrance, 1963). Dilatation of the main pulmonary artery and of the right heart are again signs of advanced disease and are not helpful for early diagnosis.
Pulmonary angiography (Chrispin et al., 1963) can be diagnostic, and is certainly essential before embolectomy is considered. However, it is not without risk in the gravely ill patient, and, again, it is not likely to be used routinely to confirm the diagnosis in a healthy patient who has just had one clinically suspicious episode. In practice it is unlikely to be used early enough or often enough to provide the type of aid to diagnosis that we are seeking.

\section{Other Diagnostic Methods}

Respiratory function studies (Robin et al., 1960 ; Jones and Goodwin, 1965) have a useful purpose in confirming a disturbance of ventilation/perfusion ratios. However, the techniques are not easy, and the procedure may be difficult in the ill patient. With increasing age interpretation of the significance of the results may be increasingly uncertain. These techniques undoubtedly have their place, but their reliability is not yet established.

Serum enzymes may be suggestive. Snodgrass et al. (1965) found elevation of the serum lactic dehydrogenase activity, an increase in the serum bilirubin concentration, and a normal serum glutamic oxalacetic transaminase activity to be helpful. However, these results may be mimicked by other medical conditions and therefore rarely provide the certainty we require.

It would appear that scanning of the lung fields after the injection of macro-aggregated radioiodinated serum human albumin (Wagner et al., 1964 ; Wagner, 1965) would be the most hopeful early diagnostic test. This radioactive material is held in the small pulmonary vessels and does not enter those blocked by embolus. This method has been shown (Sabiston and Wagner, 1965) to provide an accurate and simple method of locating areas of pulmonary arterial block and to answer most of our requirements. There would be no particular difficulty about carrying this out in the early suspected case, in the case that may have a recurrence of symptoms while on anticoagulants, or in the seriously ill patient. The equipment for this is probably now available in most teaching hospitals; the radiation involved is small, but the macro-aggregated serum albumin is at present difficult to obtain in this country. It is possible that other substances more easily handled will be developed.

\section{Predisposing Factors}

Obesity.-The fact that the body is overweight is by no means always recorded in the post-mortem or the clinical examination. Thus the observation that in the Addenbrooke's Hospital non-fatal series 11 out of $38(29 \%)$ were reported as being obese is probably of importance. Similarly, in the personal series $43 \%$ were overweight.

Venous Thrombosis.-The high incidence of obvious venous thrombosis, especially in varicose veins, with or without surgery, is remarkable. Spittell (1963) points out that superficial venous thrombosis is rarely complicated by pulmonary embolism but at any time the process may extend into the deep veins. We would therefore agree that all deep-vein thromboses, and all extending superficial venous thromboses, should be taken seriously and be treated with anticoagulants. The mere presence of varicose veins in a patient with a suspicious story increases the chances of pulmonary embolism having occurred.

Pregnancy.-There seems to be little doubt that pregnancy, particularly complicated pregnancy, is an aggravating factor in the occurrence of pulmonary embolism in young women, and in fact the only fatal case in women below the age of 45 in our series was associated with pregnancy. However, Breckenridge and Ratnoff (1964) did find 11 fatal cases in non-pregnant women. The high incidence in pregnancy may be related to the obstruction to the venous return and to the 
tendency towards thrombophlebitis (Quenneville et al., 1959), possibly aggravated by the decrease in fibrinolysins (Shaper et al., 1965) and the increase in various clotting factors (Todd et al., 1965). Oral contraceptives simulate pregnancy in this last regard (Egeberg and Owren, 1963), but it has yet to be proved that this increases the tendency to coagulation. The evaluation of any possible relation between the taking of oral contraceptives and the occurrence of pulmonary embolism will be difficult, for little is yet known about the spontaneous rate of embolism. Much further study is required.

Age and Sex.-Fatal pulmonary embolism in healthy persons can occur at any age, and we have recently heard of the case of a girl aged 18 years. However, in our series, excluding pregnancy, the majority of patients are over 40 . This is also borne out by other series. In the fatal cases the females far outweighed the males; but in the two clinical series, when the effect of pregnancy was allowed for, the distribution between the sexes was approximately equal. This would suggest that this disorder is not the precursor to "idiopathic pulmonary hypertension," where there is a heavy female preponderance.

\section{Course and Prognosis}

The good recovery of the cases in the clinical group is not remarkable when one considers the experimental (Allison et al., 1960), clinical (Sautter et al., 1964), and necropsy (Orell, 1962) evidence that pulmonary emboli are relatively rapidly absorbed and the pulmonary function soon returns to normal (Marshall et al., 1963). This is borne out by the finding of Dunér et al. $(1960 \mathrm{~b})$ that where there is a recovery from the immediate acute episode health some years later is good. Phear (1960) did not find quite such good results, and of the 68 survivors he reviewed 10 had severe disability and nine others moderate disability at an average of $\mathbf{1 7 . 6}$ months after the acute episode.

It seems that in simple major pulmonary embolus there are three possible courses.

1. There is no recurrence and the condition clears completely, often without a diagnosis having been made. This is probably the most common course.

2. The first embolus is rapidly followed by others, leading to the classical advanced picture of massive pulmonary embolus. This is often fatal, or if treatment is successful the patient may remain severely disabled or recover only after a prolonged period.

3. Further emboli are so distributed in time and space that with or without major episodes there is a gradual development of thromboembolic pulmonary hypertension (Owen et al., 1953; Wood, 1956 ; Davison et al., 1956 ; Goodwin et al., 1963). Early diagnosis and treatment are essential (Fleming, 1963) if this is to be avoided.

\section{Treatment}

Diagnosis must be made at the earliest possible time and treatment with anticoagulants instituted. In the first instance full doses of heparin must be used. Barritt and Jordan (1961), and our own experience and that of many others, have amply demonstrated the effectiveness of this treatment. If anticoagulant therapy is pushed firmly surgery to the veins or embolectomy will not commonly be necessary. The usefulness of fibrinolysins has yet to be fully confirmed.

Where possible, objective confirmation of the diagnosis will be obtained, but in its absence treatment may have to be advised on the basis of the patient's history alone. If the next episode is waited for it may be too late for treatment.

Anticoagulants should be continued for a prolonged period, but the results of the Addenbrooke's Hospital series suggest that it may not be necessary to give them for an indefinitely prolonged period in all cases. We would suggest a minimum period of three months. Then if there had been some obvious precipitating factor, such as venous thrombosis, pregnancy, or surgery, the treatment should be tailed off and the patient watched very carefully for any suggestion of recurrence. The symptoms, the physical signs, and the electrocardiogram are most important in this assessment, and here it is also anticipated that radio scanning will be useful.

Where there was no precipitating factor treatment should continue for at least six months. If there are any signs of established pulmonary hypertension, even of slight degree, anticoagulants should be continued indefinitely. In most cases it would be advisable to confirm the diagnosis by cardiac catheterization and pulmonary angiocardiography.

\section{Summary}

An investigation of post-mortem records has revealed 27 cases of massive pulmonary embolism, causing death in healthy people below the age of 70 . Clinical studies have produced 77 further non-fatal cases. Predisposing factors appear to be pregnancy, particularly complicated pregnancy, obesity, varicose veins, thrombophlebitis, and the age of 40 years or over. Six cases of isolated pulmonary hypertension could not be related to this condition.

Clinical examination with electrocardiography and chest radiography may give quite normal results until a late stage of the disorder. A reliable method of confirming the diagnosis at an early stage is essential, and it is thought that radioactive methods show great promise.

In all cases early diagnosis can be made only when the doctor has a high index of suspicion and a ready awareness of this disorder. In cases presenting to the cardiologist the importance of a story of faintness or tiredness is made clear.

Management depends on early diagnosis, so that treatment with anticoagulants may prevent a fatal outcome or the development of thromboembolic pulmonary hypertension.

We are grateful to the East Anglian Regional Hospital Board Research Fund for their generous financial support; to Dr. G. A. Gresham, Department of Morbid Anatomy, John Bonnett Clinical Laboratories, Addenbrooke's Hospital, for access to and his help with the necropsy records; to all the physicians of Addenbrooke's Hospital for permission to study their case records; to many colleagues for referring cases; and to the Misses J. Cusden and J. Fletcher for secretarial assistance.

\section{REFERENCES}

Allison, P. R., Dunnill, M. S., and Marshall, R. (1960). Thorax, 15, 273. Barritt, D. W. (1964). Postgrad. med. f., 40, 414.

- and Jordan, S. C. (1960). Lancet, i, 1309.

Brect (1961). Ibid., 1, 729.

270 270, 298.

Rad, A. R., Goodwin, J. F., and Steiner, R. E. (1963). Brit. F. Radiol., 36, 705 .

Cohen, H., and Daly, J. J. (1957). Brit. med. F., 2, 1209.

Cutforth, R. H., and Oram, S. (1958). Brit. Heart f., 20, 41.

Davison, P. H., Armitage, G. H., and McIlveen, D. J. S. (1956). Lancet, $2,224$. Dunér, H., Pernow, B., and Rignér, K. G. (1960a). Acta med. scand.,
168, 397 .

Egeberg, O., and (1960b). Ibid., 168, 381.

O., and Owren, P. A. (1963). Brit. med. F.. 1, 220.

Fleming, H. A. (1962). Lancet, 2, 45.

(1963). Brit. med. 7 .

Freiman, D. G., Suyemoto, J., and Wessler, S. (1965). New Engl. F. Med., 272, 1278.

Goodwin, J. F., Harrison, C. V., and Wilcken, D. E. L. (1963). Brit. med. F., 1, 701

Gorham, L.' W. (1961). Arch. intern. Med., 108, 8.

Hamilton, M., and Thompson, E. N. (1963). Postgrad. med. f., 39, 348. Hampton, A. O., Prandoni, A. G., and King, J. T. (1945). Bull. fohns Hopk. Hosp., 76, 245.

Homans, J. (1943). New Engl. F. Med., 229, 309.

Jones, N. L., and Goodwin, J. F. (1965). Brit. med. F., 1, 1089.

Kilburn, K. H., and Sieker, H. O. (1958). Circulation, 18, 740.

Littmann, D. (1965). In Pulmonary Embolic Disease, p. 186, edited by A. A. Sasahara and M. Stein. Grune and Stratton, New York.
. 186, edited 
Marshall, R., Sabiston, D. C., Allison, P. R., Bosman, A. R., and Dunnill, M. S. (1963). Thorax, 18, 1 .

Medd, W. E., and McBrien, D. J. (1962). Lancet, 1, 944

Morrell, M. T., Truelove, S. C., and Barr, A. (1963). Brit. med. F., 2, 830 .

Murphy, D. M. G. (1963). Ibid., 1, 1286.

Orell, S. R. (1962). Acta med. scand., 172, 473.

Owen, W. R., Thomas, W. A., Castleman, B., and Bland, E. F. (1953). New Engl. Ұ. Med., 249, 919.

Parker, B. M., and Smith, J. R. (1958). Amer. F. Med., 24, 402.

Petch, C. P. (1958). L ancet, 1, 741.

Phear, D. (1960). Ibid., 2, 832.

Quenneville, G., Barton, B., McDevitt, E., and Wright, I. S. (1959). Amer. \%. Obstet. Gynec., 77, 1135.

Robin, E. D., Forkner, C. E., Bromber, P. A., Croteau, J. R., and Travis, D. M. (1960). New Engl. F. Med., 262, 283.

Sabiston, D. C., and Wagner, H. N. (1965). \%. thorac. cardiovasc. Surg., 50, 339.

Sasahara, A. S., and Stein, M. (editors) (1965). Pulmonary Embolic Disease. Grune and Stratton, New York.

Sautter, R. D., Fletrher, F. W., Emanuel, D. A., Lawton, B. R., and Olsen, T." G. (1964). Ұ. Amer. med. Ass., 189, 948.
Shaper, A. G., MacIntosh, D. M., Evans, C. M., and Kyobe, J. (1965). Lancet, 2, 706.

Short, D. S. (1952). Brit. med. 7., 1, 790.

Smith, G. T., Dammin, G. J., and Dexter, L. (1964). F. Amer. med. Ass., 188, 143.

Snodgrass, P. J., Amador, E., and Wacker, W. E. C. (1965). In Pulmonary Embolic Disease, p. 93, edited by A. A. Sasahara and M. Stein. Grune and Stratton, New York.

Spittell. J. A. (1963). Circulation, 27, 976.

Thittell. J. A. (1963). Circulation, 27, 976.

Todd, M. E., Thompson, J. H., Bowie, E. J. W., and Owen, C. A. (1965) Mayo Clin. Proc., 40, 370

Torrance, D. J. (1963). The Chest Film in Massive Pulmonary Embolism. Thomas, Springfield, Illinois.

Wagner, H. N. (1965). In Pulmonary Embolic Disease, edited by A. A Sasahara and M. Stein, p. 225. Grune and Stratton, New York. Sabiston, D. C., McAfee, J. G., Tow, D., and Stern, H. S. (1964). New Engl. $¥$. Med., 271, 377

Wilhelmsen, L., Selander, S., Söderholm, B., Paulin, S., Varnauskas, E., and Werkö, L. (1963). Medicine (Baltimore), 42, 335 .

Wood, P. H. (1956). Diseases of the Heart and Circulation, 2nd ed. Eyre and Spottiswoode, London.

\title{
Pulmonary Emboli in Young Adults
}

\author{
C. A. LOEHRY,* M.B., M.R.C.P.
}

Brit. med. F., 1966, 1, 1327-1328

Thromboembolic disease in young patients has recently received much attention in both the popular and the medical press. There have been several reports of thrombotic episodes in young women taking oral contraceptives (Jordan, 1961 ; McIntyre et al., 1962; Richman, 1962 ; McWilliam et al., 1963 ; Reed and Coon, 1963 ; Minogue et al., 1963 ; StewartWallace, 1964 ; Schatz et al., 1964 ; Baines, 1965 ; Hartveit, 1965 ; Leather, 1965 ; Nevin et al., 1965), and it has been suggested that the drug may be responsible for intravascular thrombosis. It is, however, possible that the association is fortuitous, and that there has recently been an increased awareness of thromboembolic disease or an increase in the number of young adults suffering from the condition. It has been a clinical impression, while working in the medical wards, that an ever-increasing number of young patients with pulmonary emboli have been admitted in recent years. In order to study this further, the notes were obtained of all in-patients at St. Thomas's Hospital since 1956 diagnosed as cases of pulmonary emboli and under the age of 40 . The present report is an analysis of this group of young patients in the 11-year period from 1954 to 1964 , which is the latest date that accurately filed records are as yet available.

\section{Results}

After careful examination of the notes 94 patients were considered to have good evidence of emboli. Of these, 85 showed signs of pulmonary infarction, with pleuritic pain in every case, mostly with haemoptysis, and often with radiographic appearances of small transient areas of consolidation. Seven patients had massive emboli, with shock or syncopal attacks, and both clinical and electrocardiographic evidence of right auricular and ventricular strain. Of this group five subsequently died, and pulmonary emboli were demonstrated at necropsy. Two further cases were diagnosed only at necropsy. Altogether 58 patients had evidence of venous thrombosis in the legs, though in several of them this postdated the embolic episode. The 94 patients were divided into two groups: in 62 cases additional features were present which

* Medical Registrar, St. Thomas's Hospital, London. Now at the Royal South Hants Hospital, So:Ithampton. are known to predispose to thromboembolic disease, such as a recent operation, congestive cardiac failure, trauma, and pregnancy; in the remaining 32 cases there were no apparent precipitating features. The numbers of cases in both groups for each year since 1954 are given in the Table.

\begin{tabular}{c|c|c|c}
\multicolumn{4}{c}{ Incidence of Pulmonary Emboli in Young Adults } \\
\hline Year & $\begin{array}{c}\text { Idiopathic } \\
\text { Group }\end{array}$ & $\begin{array}{c}\text { Other Factors } \\
\text { Present }\end{array}$ & $\begin{array}{c}\text { In-patient Population } \\
\text { at St. Thomas's }\end{array}$ \\
\hline 1954 & 0 & 2 & 18,279 \\
1955 & 0 & 6 & 18,375 \\
1956 & 1 & 5 & 19,245 \\
1957 & 1 & 5 & 19,739 \\
1958 & 0 & 3 & 19,626 \\
1959 & 1 & 3 & 19,765 \\
1960 & 2 & 5 & 20,351 \\
1961 & 3 & 4 & 21,1926 \\
1962 & 4 & 11 & 21,207 \\
1963 & 8 & 10 & 21,136 \\
1964 & 12 & & \\
\hline
\end{tabular}

The most striking feature is the increased incidence of pulmonary emboli in these young patients since 1961. There has been some increase in both groups, but this is most pronounced in the idiopathic cases. In 1963 alone there were eight such patients, and in 1964 a further 12 who had previously been in good health and presented with emboli but no apparent precipitating cause, while there were no patients in this group in 1954 and 1955. Among the 62 cases complicated by other factors 34 had recently had an operation, 10 were in cardiac failure from rheumatic heart disease, six had recently been involved in an accident affecting their lower limbs, four were in the post-partum period, one had neoplastic disease, and seven were suffering from some other chronic medical condition.

The numbers of cases in both groups are compared with age (see Fig.). It is well recognized that older patients are more likely to develop thrombotic disease, and this is confirmed here in the "secondary" group, where there is a sharp rise in the number of cases after the age of 30 . It is interesting that in the idiopathic group there was little difference in the number of patients in any age group. Though the number of cases in this group is not large, there is perhaps a suggestion from the evidence that different factors may be responsible here which are not influenced by age. There was little sex difference 